\title{
Preparation of Activated Carbon Derived from Rice Husk by Simple Carbonization and Chemical Activation for Using as Gasoline Adsorbent
}

\author{
Arunrat Cheenmatchaya and Sukjit Kungwankunakorn
}

\begin{abstract}
Rice from Thailand is the top ranking of the world. The by-product of rice manufacturing is rice husk, which its usefulness is not fully attempt. The aims of research are to make value-added activated carbons of rice husk and to study the optimum conditions for gasoline adsorption using these activated carbons as adsorbents. All samples were analyzed for gasoline adsorption by gas chromatograph-mass spectrometry (GC-MS). The activated carbon of rice husk, which activated by $\mathrm{H}_{3} \mathrm{PO}_{4}$ at temperature of $450{ }^{\circ} \mathrm{C}$, has the highest adsorption capacity. According to gasoline adsorption study, the optimum conditions were $0.1 \mathrm{~g}$ of activated carbon, $70{ }^{\circ} \mathrm{C}$ of adsorption temperature and 30 minutes of adsorption time. Physical characterization of the activated carbon obtained was performed by scanning electron microscopy (SEM). The results present that the activated carbon of rice husk possesses a high apparent surface area $\left(S_{\mathrm{BET}}=336.35 \mathrm{~m}^{2} / \mathrm{g}\right)$. They thus encourage the use of activated carbon of rice husk as an adsorbent for the qualitative analysis of gasoline in order to apply for gasoline sampling in arson case and to reduce the analysis cost from commercial adsorbent.
\end{abstract}

Index Terms-Rice husk, activated carbon, gasoline, adsorption.

\section{INTRODUCTION}

Rice is regarded as main food of Thai people for a long time. Beside domestic consumption, rice is a major agricultural product that extremely high exportation value. In rice manufacturing, rice husk is the by-product from paddy grinding. So far, rice husk has been successfully used as fuel in many industrial factories and used as biomass fuel in electricity generating [1] because of its low humidity and simple operation. Not only rice husk, their charcoal that obtained from combustion step is also versatile. Both rice husk and rice husk charcoal have major components namely, carbon and silica. They have been found to be suitable materials owing to their high carbon and silica and low ash contents. Consequently, they are determined to be the precursors used for the production of activated carbon that commonly used as adsorbents. Activated carbons have exceptional adsorption properties because of their high surface area, large adsorption capacity and fast adsorption kinetics [2]. From previous studies, many agricultural wastes such as Jatropha curcas fruit shell [2], coconut shell [3], corn cob [4], Dendrocalamus asper Baker and Dendrocalamus

\footnotetext{
Manuscript received August 15, 2013; revised September 27, 2013. This work was supported by the Institute for the Promotion of Teaching Science and Technology (IPST).

The authors are with the Chemistry Department, Chiang Mai University, Chiangmai, Thailand (e-mail: arunrat_chem@ hotmail.com, ksukjit@hotmail.com).
}

Latiflorus [5], mangosteen shell [6], oil plam shell [7] and jackfruit shell [8] have been studied for preparation of activated carbon because of their proper properties. Thus, a possible solving of rice husk is converting it into value-added activated carbon used as adsorbents. In other words, the expensive commercial activated carbon will be reduced. Normally, the manufacturing of activated carbons involves two major processes, carbonization of raw carbonaceous materials in an inert atmosphere and activation of the carbonized product. The activation process can be divided by two types; physical activation and chemical activation. However, chemical activation is widely applied because of its lower activation temperature and higher product yield compared with physical activation [2]. With many earlier studies, the activated carbons from agricultural wastes were always studied on its characteristic and adsorption efficiency. Many indicators such as iodine [2], methylene blue [2], congo red [1] and metal ions such as cadmium [9] were used to determine adsorption efficiency.

The aims of this work were to utilize rice husk, agricultural waste, for the preparation of activated carbon by either carbonization or chemical activation using $\mathrm{H}_{3} \mathrm{PO}_{4}$ as an activating agent. The carbonized rice husk and chemical activated rice husk were applied to use as gasoline adsorbents for adsorption efficiency determination. In this work, SEM technique and BET theory were employed to determine the physical characterization of studied adsorbent for the purpose of noncommercial adsorbents developing for gasoline sampling in forensic science.

\section{EXPERIMENTAL}

\section{A. Material}

Rice husk was collected from rice mill in Lamphun Province, Thailand. In this study, gasoline was selected to be an adsorbate as it was found in arson scene frequently. Due to low flash point and availability, gasoline was a good accelerant. Gasohol 95 was obtained from petrol station in Lamphun Province, Thailand.

\section{B. Instrumentations}

All samples were analyzed by gas chromatograph-mass spectrometry (Agilent 6850-5973N, U.S.A.) which is used in the entire experiment. The HP-5ms column (Agilent, U.S.A.) was employed. The injector port was set at $150{ }^{\circ} \mathrm{C}$ and the carrier gas used was He at a constant flow of $1.0 \mathrm{~mL} / \mathrm{min}$. The split ratio was 200:1 and the electron impact mode was applied for MS operation, choosing $70 \mathrm{eV}$ as the electron energies, while the ion source temperature was set at $230^{\circ} \mathrm{C}$. 
The solvent delay was $1.30 \mathrm{~min}$. The details of the program used in GC-MS analysis were as follows: the initial temperature of the $\mathrm{GC}$ oven is $100^{\circ} \mathrm{C}$ and hold for $2 \mathrm{~min}$. The temperature was increased from 100 to $200{ }^{\circ} \mathrm{C}$ at a rate of 20 ${ }^{\circ} \mathrm{C} / \mathrm{min}$ and hold at $200{ }^{\circ} \mathrm{C}$. The total run time was $8.30 \mathrm{~min}$.

\section{Carbonization of Rice Husk}

The $20 \mathrm{~g}$ of rice husk samples were carbonized at 200 and $400{ }^{\circ} \mathrm{C}$ for $1 \mathrm{hr}$ in a muffle furnace (Barnstead, IA U.S.A.) in order to produce charcoal. The sample was crushed with blender and sieved to a size smaller than $850 \mu \mathrm{m}$ to obtain the charcoal of rice husk $(\mathrm{CRH})$.

\section{Chemical Activation of Rice Husk}

The $100 \mathrm{~g}$ of rice husk was subjected impregnation in 1 $\mathrm{dm}^{3}$ of 3 molar $\mathrm{H}_{3} \mathrm{PO}_{4}$ at $80{ }^{\circ} \mathrm{C}$ for $3 \mathrm{hr}$. After that, it was cleaned with DI water until its $\mathrm{pH}$ value was 7 . The sample was dried at $100{ }^{\circ} \mathrm{C}$ for $24 \mathrm{hr}$. The $22 \mathrm{~g}$ of dried samples were carbonized at 450 and $700{ }^{\circ} \mathrm{C}$ for $2 \mathrm{hr}$ in a muffle furnace (Barnstead, IA U.S.A.). The charcoal was crushed and sieved to a size smaller than $850 \mu \mathrm{m}$ to obtain the activated carbon of rice husk (ACRH).

\section{OPTIMUM GASOLINE ADSORPTION CONDITIONS FOR ACTIVATED CARBON OF RICE HUSK}

Some parameters which had effect on the gasoline adsorption for activated carbon of rice husk namely type of adsorbent (CRH200, CRH400, ACRH450 and ACRH700), amount of adsorbent (0.05-0.4 g), adsorption temperature $\left(60-90{ }^{\circ} \mathrm{C}\right)$ and adsorption time (10 min-24 hr) were studied to determine the optimal conditions for gasoline adsorption.

For adsorption and desorption procedures, activated carbons of rice husk were filled in tea bags and hung in the containers. The containers contained soil that spiked with 10 $\mu \mathrm{g} / \mathrm{mL}$ gasoline. The samples were took to the oven (Memmert, Germany) at given adsorption temperature for given adsorption time. After that, dichloromethane was used as solvent desorber for analysis of gasoline by GC-MS technique.

Microstructure of the samples was examined using a scanning electron microscopy (Jeol JSM-5410LV, Japan).

In this work, gasoline adsorption efficiency of activated carbon of rice husk was considered by various equations for each parameter.

\section{A. The Relative Signal Value}

To make the comparison of adsorption efficiency of investigated adsorbents easier, the relative signal value was calculated;

$$
\text { The relative signal value }=\frac{x}{y} \times 100
$$

where $x$ is the mean signal value for the compound and investigated adsorbent; $y$ is the mean signal value for the same compound and adsorbent that turn out to be more effective with relation to this compound [10].

\section{B. The Equilibrium Adsorption Capacity $\left(q_{e}\right)$}

For the study of amount of adsorbent, adsorption temperature and adsorption time, the equilibrium adsorption capacities $\left(q_{e}\right)$ of the activated carbon of rice husk were determined based on adsorbent mass balance using equation;

$$
q_{e}=\frac{\left(C_{0}-C_{e}\right) V}{M}
$$

where $C_{\mathrm{o}}$ and $C_{\mathrm{e}}$ are the initial and equilibrium concentrations of the gasoline $(\mathrm{mg} / \mathrm{L})$, respectively, $V$ is the volume of the dichloromethane (L) and $M$ is the mass of adsorbent used $(\mathrm{g})$ [11].

\section{RESUlTS AND DisCUSSION}

\section{A. Type of Adsorbent}

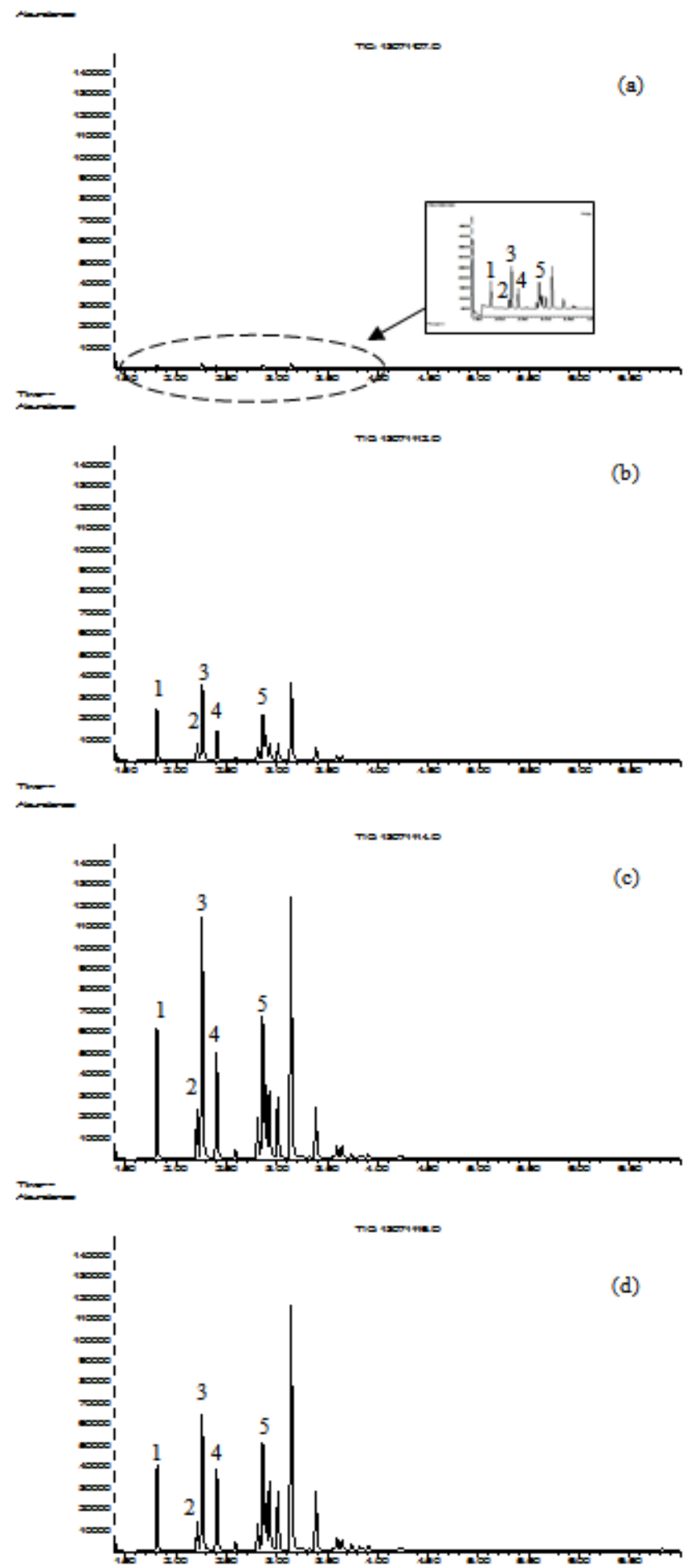

Fig. 1. Representative chromatograms comparing the amount of gasoline for CRH200 (a), CRH400 (b), ACRH450 (c) and ACRH700 (d). 
Examples of obtained chromatograms are shown in Fig. 1.

The 5 characteristic peaks of gasoline as listed in Table I were investigated [12]. Evaluating the adsorption efficiency of the 4 types of adsorbent for these compounds allows one to estimate their suitability for the analysis of gasoline.

\begin{tabular}{llll}
\multicolumn{4}{c}{ TABLE I: THE 5 CHARACTERISTIC PEAKS OF GASOLINE } \\
\hline \hline Number & Name & Retention time (min) & Formula \\
\hline 1 & Toluene & 1.803 & $\mathrm{C}_{7} \mathrm{H}_{8}$ \\
2 & Ethylbenzene & 2.133 & $\mathrm{C}_{8} \mathrm{H}_{10}$ \\
3 & Xylene & 2.171 & $\mathrm{C}_{8} \mathrm{H}_{10}$ \\
4 & O-xylene & 2.301 & $\mathrm{C}_{8} \mathrm{H}_{10}$ \\
5 & 3-ethyltoluene & 2.690 & $\mathrm{C}_{9} \mathrm{H}_{12}$ \\
\hline \hline
\end{tabular}

The results obtained are presented graphically. Fig. 2 presents the relative signal values of 4 types of adsorbent. The uncertainty of the obtained relative signal values was calculated on the basis of the standard derivation of means.

For CRH200, all of these compounds except 3-ethyltoluene was hardly adsorbed. Because CRH200 has unsuitable physical properties due to its low carbonization temperature, which used to produce the charcoal.

The results in Fig. 2 showed that ACRH450 turned out to be more effective for the adsorption of gasoline than others.

SEM photographs in Fig. 3 show that the ACRH450 adsorbent (c) gives the texture with heterogeneous surface and a variety of randomly distributed pore size. Furthermore, it composes of an irregular and highly porous surface, indicating relatively high surface area. This result can be support by BET surface area of ACRH450 which is 336.35 $\mathrm{m}^{2} / \mathrm{g}$.

Therefore, the ACRH450 adsorbent was chosen as the optimum condition for further experiments.

\section{B. Amount of Adsorbent}

Theoretically, with increase of amount of adsorbent, the adsorption became more intensive due to more amount resulting in an increased surface area which was considered to be the most important factor for adsorption. However, when considering the $q_{e}$ value that based on adsorbent mass balance, the results showed that unless the toluene compound, the $q_{e}$ values of 0.05 and $0.1 \mathrm{~g}$ of adsorbent were nearly the same. Ethylbenzene and 3-ethyltoluene which could remain after extinguishment as reported previously [13] were used to determine the conclusion.

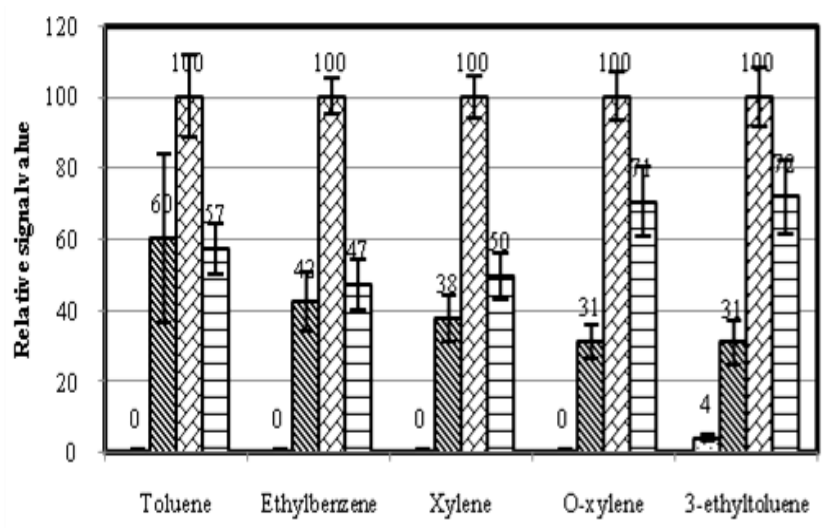

वCRH $200 \quad \mathbb{C} \mathrm{CRH} 400 \quad$ बACRH450 वACRH 700

Fig. 2. The bar graphs illustrate the effectiveness of CRH200, CRH400, ACRH450 and ACRH700 in the adsorption of gasoline.
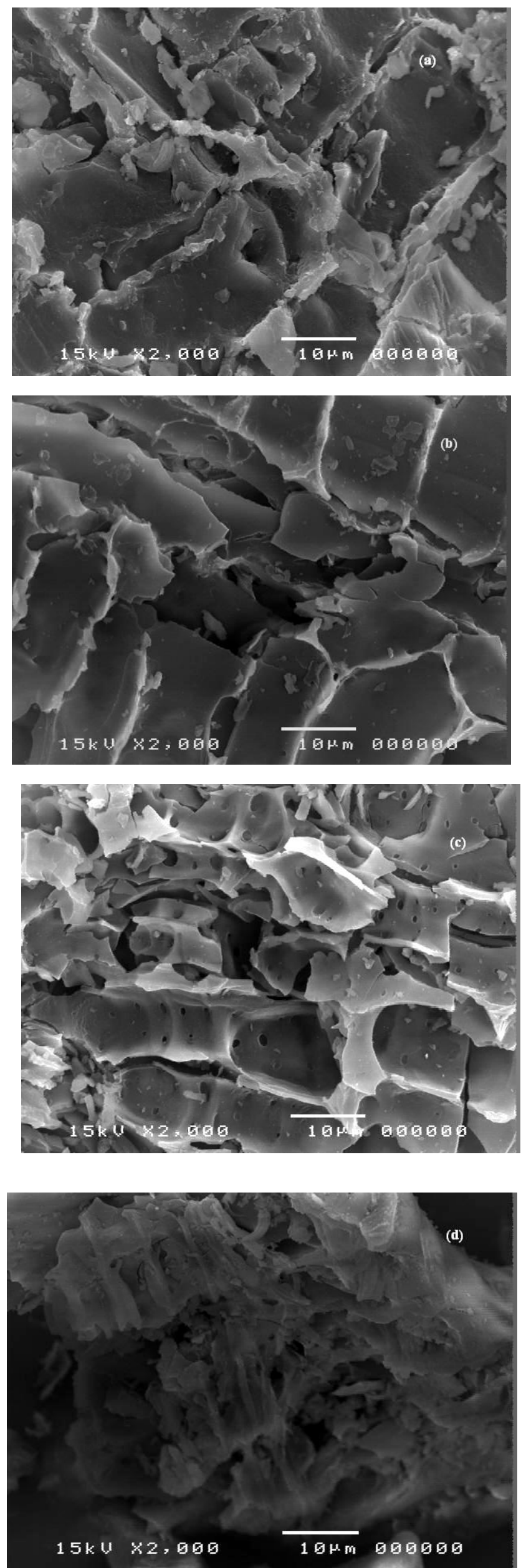

Fig. 3. SEM photographs of CRH200 (a), CRH400 (b), ACRH450 (c) and ACRH700 (d). 
From the results as shown in Fig. 4, it illustrated that the highest $q_{e}$ values of ethylbenzene and 3-ethyltoluene were obtained when using $0.1 \mathrm{~g}$ of adsorbent. Thus, $0.1 \mathrm{~g}$ of adsorbent was chosen as the optimum amount of adsorbent.

\section{Adsorption Temperature}

The effect of adsorption temperature on $q_{e}$ value is illustrated in Fig. 5. It was shown that increasing in the adsorption temperature resulted in the decreasing in $q_{e}$ value. This trend is expected because gasoline which had high vapor density could evaporate more with high temperature, so the adsorbent could not adsorb well.

The results present that instead of $60{ }^{\circ} \mathrm{C}, 70{ }^{\circ} \mathrm{C}$ is the suitable temperature for gasoline adsorption because it gave the highest $q_{e}$ value of ethylbenzene and 3-ethyltoluene. The adsorption temperature at $60{ }^{\circ} \mathrm{C}$ could not be adequate for ethylbenzene and 3-ethyltoluene that had a high boiling point. Although 3-ethyltoluene had the highest $q_{e}$ value at 80 ${ }^{\circ} \mathrm{C}$, the standard deviation that observed from the error bar in the graph has shown that the variance of $q_{e}$ value has a wide range. This is why $70{ }^{\circ} \mathrm{C}$ seems to be the most proper adsorption temperature for activated carbon of rice husk.

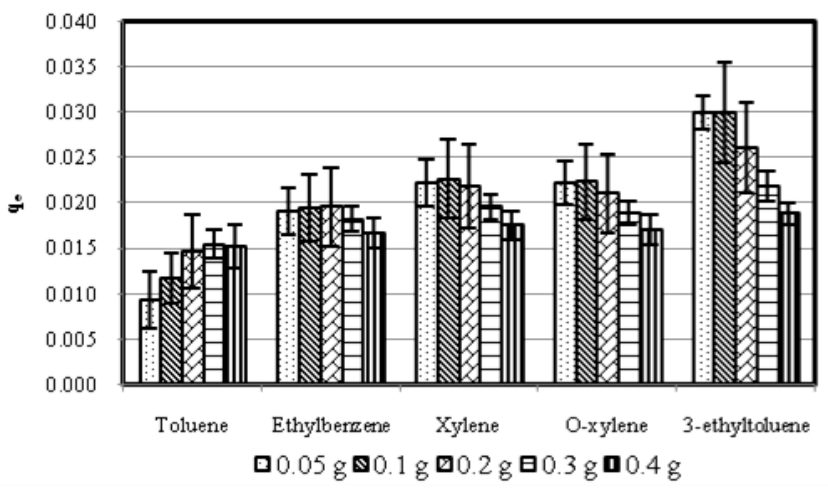

Fig. 4. The bar graphs illustrate the $q_{e}$ values of various amounts of adsorbent.

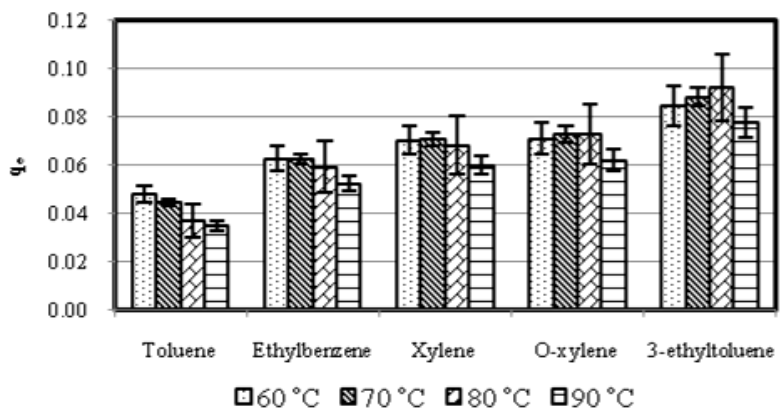

Fig. 5. The bar graphs illustrate the $q_{e}$ values of various adsorption temperatures.

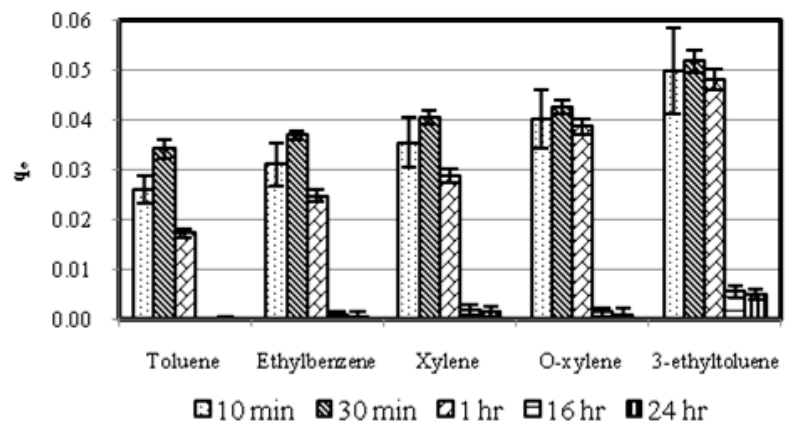

Fig. 6. The bar graphs illustrate the $q_{e}$ values of various adsorption times.

\section{Adsorption Time}

For the study on adsorption time, the results showed that increasing in adsorption time significantly decreased in $q_{e}$ value, which related to the results of adsorption temperature. This was due to the desorption, which might occur with the high vapor density substance such as gasoline, rate of desorption at long adsorption time was higher than that at short adsorption time, then the possibility of gasoline leak would be occurred.

As shown in Fig. 6, the $q_{e}$ value of $10 \mathrm{~min}$, the shortest time in this study, was not the most suitable condition among the investigated adsorption times. The reason is that $10 \mathrm{~min}$ was insufficient for evaporation and adsorption of gasoline in a container. A small amount of gasoline was adsorbed during this period. Consequently, the optimum adsorption time for gasoline adsorption was $30 \mathrm{~min}$.

In this study, the amounts of gasoline detected by GC-MS that represented in term of $q_{e}$ values were much lower than spiked amount due to their volatile property. However, this study focused on the qualitative analysis that can be used to identify gasoline in arson cases. So, the activated carbon of rice husk which could adsorb gasoline and show all 5 characteristic peaks deserved to be the gasoline adsorbent.

\section{CONCLUSION}

The value-added activated carbon of rice husk can be produced by simple carbonization-chemical activation. Carbonization at $450{ }^{\circ} \mathrm{C}$ for $2 \mathrm{hr}$ and using $\mathrm{H}_{3} \mathrm{PO}_{4}$ as an activating agent was a suitable process. Under these optimum conditions, BET surface area of the activated carbon of rice husk was $336.35 \mathrm{~m}^{2} / \mathrm{g}$. The adsorption efficiency of activated carbon of rice husk which has the highest gasoline adsorption was obtained when using $0.1 \mathrm{~g}$ of ACRH450 as adsorbent at $70{ }^{\circ} \mathrm{C}$ adsorption temperature for $30 \mathrm{~min}$ of adsorption time. Since the activated carbon of rice husk is high surface area and gasoline adsorption capacity, therefore, it can be employed as noncommercial adsorbent and considered as an alternative one to commercial adsorbent. For further research, these optimum conditions for gasoline adsorption using activated carbon of rice husk as adsorbent will be used for the study of residual gasoline detection in soil samples as duplicated evidence in arson scenes.

\section{ACKNOWLEDGMENT}

The authors acknowledge stimulating discussions with the group of Sukjit's laboratory on the topics reported in this study.

\section{REFERENCES}

[1] P. Jintanawasan, W. Clowutimon, and P. Assawasaengrat, "Adsorption of congo red by rice husk," presented at the TIChE Conference, Songkhla, Thailand, November 10-11, 2011.

[2] W. Tongpoothorn, M. Sriuttha, P. Homchan, S. Chanthai, and C. Ruangviriyachai, "Preparation of activated carbon derived from Jatropha curcas fruit shell by simple thermo-chemical activation and characterization of their physico-chemical properties," Chem. Eng. Res. Des., vol. 89, pp. 335-340, March 2011.

[3] Z. Hu and M. P. Srinivasan, "Preparation of high-surface-area activated carbons from coconut shell," Micropor. Mesopor. Mater., vol. 27, pp. 11-18, January 1999.

[4] W. T. Tsai, C. Y. Chang, and S. L. Lee, "A low cost adsorbent from agricultural waste corn cob by zinc chloride activation," Bioresour. Technol., vol. 64, pp. 211-217, June 1998. 
[5] P. Temyarasilp, "Preparation and characterization of activated carbon from Dendrocalamus asper Backer and Dendrocalamus Latiflorus," M. S. thesis, Dept. Chem., Kasetsart Univ., Bangkok, Thailand, 2008.

[6] P. Sukananta, "Investigation of surface property and characteristic of the activated carbon from mangosteen shell prepared by the single and two stage," Agric. Sci. J., vol. 41, pp. 285-288, 2010.

[7] I. A. W. Tan, A. L. Ahmad, and B. H. Hameed, "Enhancement of basic dye adsorption uptake from aqueous solutions using chemically modified oil palm shell activated carbon," Colloids Surf., A, vol. 318 pp. 88-96, April 2008.

[8] D. Prahas, Y. Kartika, N. Indraswati, and S. Ismadji “"Activated carbon from jackfruit peel waste by $\mathrm{H}_{3} \mathrm{PO}_{4}$ chemical activation: pore structure and surface chemistry characterization," Chem. Eng. J., vol. 140, pp. 32-42, July 2008

[9] J. Chompunuch and N. Amornkarnjanawat, "Preparation of activated carbon from rice husk ash,” B. S. Special Problem, Dept. Chem. and Mater. Eng., Rangsit Univ., Bangkok, Thailand, 2005.

[10] R. Borusiewicz and J. Zieba-Palas, "Comparison of the effectiveness of Tenax $\mathrm{TA}^{\circledast}$ and Carbotrap $300^{\circledR}$ in concentration of flammable liquids compounds," J. Forensic Sci., vol. 52, pp. 70-74, January 2007.

[11] B. G. P. Kumar, L. R. Miranda and M. Velan, "Adsorption of Bismark Brown dye on activated carbons prepared from rubberwood sawdust (Hevea brasiliensis) using different activation methods," J. Hazard. Mater., vol. 126, pp. 63-70, November 2005.
[12] J. Raruenrom, "Application of activated carbon in the identification of flammable liquids," M. S. thesis, Dept. Forensic Sci., Silpakorn Univ., Bangkok, Thailand, 2008.

[13] L. Dong, S. Hao et al., "An analysis of background interference on fire debris," Procedia Eng., vol. 52, pp. 664-670, 2013.

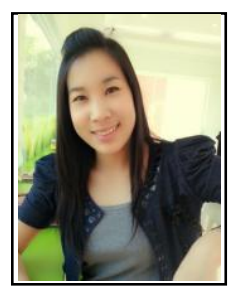

Arunrat Cheenmatchaya was born in Lamphun Province, Thailand in 1984. She received the B.Sc. degree and M.Sc. degree in chemistry from Chiang Mai University, Chiang Mai, Thailand in 2006 and 2009 , respectively.

From 2003 to 2006, she worked the research about elimination of lead, cadmium, copper and chromium in wastewater by corn cobs as adsorbent. For M. Sc. degree, she joined the Western Digital (Thailand) company limited for research cooperation about recycling of halogenated organic solvents, which used as electronic part cleaning solvent.

Ms. Cheenmatchaya has got a scholarship from The Institute for the Promotion of Teaching Science and Technology (IPST), the Thai government scholarship since 2005. 